\title{
BIOECONOMICS OF MANAGING THE SPREAD OF EXOTIC PEST SPECIES WITH BARRIER ZONES
}

\author{
Alexei A. Sharov ${ }^{1}$ And Andrew M. Liebhold ${ }^{2}$ \\ ${ }^{1}$ Department of Entomology, Virginia Polytechnic Institute and State University, Blacksburg, Virginia 24061 USA \\ ${ }^{2}$ Northeastern Forest Experiment Station, USDA Forest Service, 180 Canfield Street, \\ Morgantown, West Virginia 26505 USA
}

\begin{abstract}
Exotic pests are serious threats to North American ecosystems; thus, economic analysis of decisions about eradication, stopping, or slowing their spread may be critical to ecosystem management. We present a model to analyze costs and benefits of altering the spread rates of invading organisms. The target rate of population expansion (which may be positive or negative) is considered as a control function, and the present value of net benefits from managing population spread is the criterion that is maximized. Two local maxima of the present value of net benefits are possible: one for eradication and another for slowing the spread. If both maxima are present, their heights are compared, and the strategy that corresponds to a higher value is selected. The optimal strategy changes from eradication to slowing the spread to finally doing nothing, as the area occupied by the species increases, the negative impact of the pest per unit area decreases, or the discount rate increases. The model shows that slowing population spread is a viable strategy of pest control even when a relatively small area remains uninfested. Stopping population spread is not an optimal strategy unless natural barriers to population spread exist. The model is applied to managing the spread of gypsy moth (Lymantria dispar) populations in the United States.
\end{abstract}

Key words: barrier zone; bioeconomics; biological invasion; cost-benefit model; eradication; exotic species; gypsy moth; Lymantria dispar; pest control; spread rate.

\section{INTRODUCTION}

Bioeconomics, a theory of optimal management of renewable biological resources, has been largely applied in fisheries and aquaculture (Clark 1976, Allen et al. 1984). Initial bioeconomic models in fisheries were based on the concept of maximum sustainable yield, which implies a stable equilibrium. However, natural populations often have non-equilibria dynamics. For example, local population dynamics may exhibit complex patterns, such as limit cycles and chaos (Turchin and Taylor 1992). Exotic species may expand their range in space by forming nonstationary waves (Skellam 1951). Economic assessment of these transition processes requires incorporation of discount (inflation) rates into cost-benefit analyses that can be accomplished using present values. The present value of an activity equals the net expected revenues weighted by the exponential function of the time at which these revenues are obtained (Clark 1976):

$$
\int_{0}^{T} P(t) \exp (-\alpha t) d t
$$

where $P(t)$ are net revenues at time $t, \alpha$ is the discount rate, and $T$ is the time horizon. The time horizon may be infinite; in this case, a criterion of convergence is

Manuscript received 23 May 1997; revised 19 November 1997; accepted 26 November 1997. required. Revenues, $P(t)$, can be both positive and negative. Typically, discount rates vary from 0.02 to 0.07 per year.

Bioeconomics has previously been applied to insect pest management (Hall 1974, Stern 1975). However, most bioeconomic models in pest management considered only short-term revenues. For example, the concept of the economic injury level, which is the cornerstone of integrated pest management (IPM), is usually applied to one growing season (Stern et al. 1959, Pedigo 1985). In many agricultural programs, the time span between investment in pest management and harvest of the crop is short, and there is no need to use the concept of present value because inflation is negligible during this period. Thus, most optimization models in pest management have concentrated on maximizing the difference between benefits and costs in the same year (Goh 1980, Shoemaker and Onstad 1983, Gutierrez and Wang 1984).

However, some pest management activities have long-term consequences and, thus, the economic analysis should cover a longer period. For example, although the suppression of forest pest insect populations using chemical sprays may protect foliage in the year of application, it may also increase the chances of outbreaks in subsequent years (Isaev et al. 1984). Shortterm objectives, e.g., prevention of defoliation, might not be optimal over an extended period. Another reason for considering the economic effects of forest pest man- 
agement over a long term is that revenues are typically delayed until the forest matures (Leuschner and Berck 1985). Long-term optimization may be necessary in agricultural pest management if it has delayed effects (e.g., increasing resistance to pesticides). For example, Plant et al. (1985) found that optimal timing of suppression of spider mites depended on a trade-off between gaining a high yield in the current harvest and preventing the development of resistance to pesticides, which would affect future yields.

The concept of present value has not been used for optimization of pest management programs. Leuschner et al. (1996) used discounting in evaluating potential benefits from slowing the spread of gypsy moth, $L y$ mantria dispar (L.), populations in North America. However, these authors did not use optimization. It is clear that long-term pest management programs would benefit from a broader adoption of bioeconomic concepts, especially the concept of present value.

In this paper, we apply the concept of present value to the problem of managing the spread of exotic pest species using barrier zones. Exotic pests are serious threats to North American ecosystems (Sailer 1983, Liebhold et al. 1995). Because of increasing transportation activity, the risk of invasion by moving organisms across natural geographic barriers is growing. For a variety of reasons, introduced species are more likely to be pests than are native species (Simberloff 1986). The percentage of imported species is $39 \%$ among agricultural pest insects (Sailer 1983), and 27\% among forest pest insects (Pimentel 1986).

Traditionally, quarantine programs have been based upon qualitative understanding of economic effects, and most decisions have been based on intuition. Attempts to apply economic analysis to quarantine measures have often failed because of insufficient information and unjustified simplifications (Dahlsten et al. 1989, LeVeen 1989). For example, side effects of largescale pesticide treatments were ignored in cost-benefit analyses of several eradication programs (Dahlsten et al. 1989). Monitoring systems were often inefficient, and the range of a species could have been underestimated. However, new technologies (efficient traps, geographic information systems, etc.) provide tools for effective economic analysis of quarantine activities. Information on the ecological effects of many invading pest species has substantially increased over the last decade, making economic analyses possible.

When an exotic pest species becomes established, various strategies can be used to change the rate of expansion of the population range, including reduction of the chances of accidental movement of organisms to the uninfested area via domestic quarantine, detection and eradication of isolated colonies in the uninfested area, establishment of barrier zones designed for slowing or stopping population spread, or eradication of the entire pest population, if possible. Simultaneous analysis of all of these options would lead to compli- cated models that are difficult to analyze theoretically. We believe that attempts to combine these options should be preceded by studies of individual management options. In this paper, we consider just one kind of activity: barrier zones.

Any pest management activity performed in the area adjacent to the population front and targeted at modification of the rate of population spread can be considered as a form of barrier zone management. Barrier zones can be stationary or moving. For example, a stationary barrier zone was established to prevent the migration of the screwworm, Cochliomyia hominivorax (Coquerel), from Mexico to the United States (Marsula and Wissel 1994). Several barrier zones that were established in 1992 to slow the spread of gypsy moth populations in Virginia, West Virginia, and North Carolina will eventually move in the direction of population spread (Leonard and Sharov 1995). A barrier zone may also be shifted backwards in order to eventually eradicate the entire population. The boll weevil, Anthonomus grandis Boheman, eradication program (Coppedge 1996) can be considered as an example of this type of effort.

The management of barrier zones evokes several questions that are of great public concern. First, how extensive must a population be before eradication is no longer a viable approach? The decision is often painful, because the inability to eradicate the pest is considered as a failure. However, it may happen that the present value of eradication is lower than the present value of alternative strategies, such as slowing the spread. Second, are efforts to slow population spread economically viable? Slowing the rate at which pest populations are spreading may not be considered beneficial because the pest will eventually occupy its entire potential range. This argument is based on the equilibrium economics that ignores transition processes. The concept of present value helps to justify the economics of transition processes, such as slowing population spread. Third, the idea of stopping population spread has been very attractive, but its economic viability has never been thoroughly evaluated. Alternative strategies (e.g., slowing the spread or gradual eradication) may have a greater present value than stopping the spread.

We use the problem of gypsy moth spread in North America as a case study. The gypsy moth is a good species for this analysis because: (1) considerable resources are currently being expended on slowing the spread of the gypsy moth through North America, and (2) historical data that describe its spread are probably more extensive in both space and time than for any other invading species.

\section{General Model of a Barrier Zone}

Let us assume that a continuous area potentially can be invaded by a pest species. The pest can be introduced in the center of this area (Fig. 1A), at the edge (Fig. 
FIG. 1. Three types of pest introduction: (A) in the center of potential species' range; (B) at the edge; and (C) in a linear area.
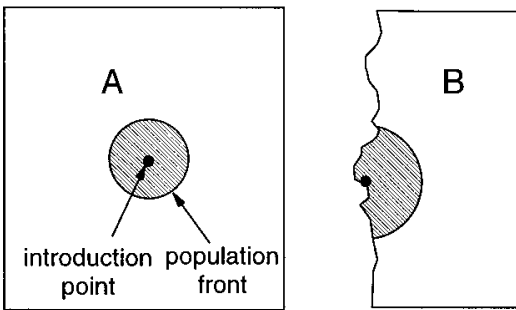

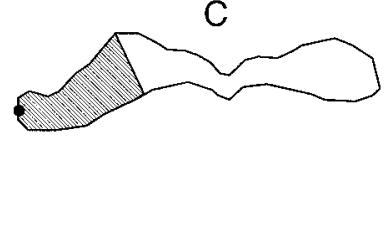

1B), or at the end of the linear area (Fig. 1C). Here, we do not consider species that live in highly isolated habitats (e.g., rivers, lakes).

We further assume that the rate of uncontrolled spread, $v_{\max }$, is constant. In reality, $v_{\max }$ may vary in time and space. For example, the rate of population spread may increase with the time elapsed since initial introduction (Hastings 1996, Shigesada et al. 1995). Also, the rate of spread may depend on the physical environment or landscape characteristics. However, for theoretical purposes it is more convenient to assume a constant $v_{\max }$. Simplified theoretical models often can be adjusted to fit specific conditions in real populations. For example, if the rate of population spread in one direction is different from the rate of spread in another direction, these directions can be considered individually, and optimization may result in different management strategies in each direction.

Let us plot the length of the population front, $L(x)$, as a function of the distance from the introduction point (Fig. 2). The shape of function $L(x)$ depends on the shape of the area that potentially can become infested and on the location of the introduction point (Fig. 1). If the invasion occurs in the center of the potential range (Fig. 1A), then $L(x)=2 \pi x$ for small values of $x$. When the population front reaches the boundary of the potential species' range, however, the length of the population front is no longer proportional to the distance from the introduction point. We assume that the area has a simple shape (i.e., no deep bends or large gaps), so that the direction of population expansion remains the same. In practical situations, the current population front of a species might be noncircular. Then the distance, $x$, can be measured from the current front line rather than from the introduction point.

We can simplify the problem by assuming that the potential species' range is represented by the area between the function, $L(x)$, and the horizontal axis in Fig. 2 . Then, the population front can be viewed as a vertical line that moves from left to right. The length of this line is equal to the length of the population front, $L\left(x^{\prime}\right)$, at distance $x^{\prime}$; the area to the left of this line, $\int_{0}^{x^{\prime}} L(x)$ $d x$, is equal to the area occupied by the population when the front is located at distance $x^{\prime}$. In the same way, the area to the right of the vertical line $x=x^{\prime}$ is equal to the area not occupied. Costs and benefits from managing population spread depend on the length of the population front and on areas that are occupied and unoccupied. Thus, the model in Fig. 2 can be used to estimate costs and benefits from managing the spread of a population in all types of species introductions (Fig. 1A-C).

The next step is to consider a barrier zone set along the population front in order to modify the rate of spread. The distance from the introduction point to the population front, $x(t)$, is a function of time since introduction, $t$. The rate of spread, $v(t)=d x / d t$, is the derivative of function $x(t)$. The cost of the barrier zone per unit length along the population front, $C(v)$, represents the minimum cost of maintaining the target rate of population spread, $v$, which means that all activities in the barrier zone are optimized. The function $C(v)$ is likely to decrease as the target rate of spread increases (Fig. 3). If the target rate of spread is equal to the rate of uncontrolled spread, there is no need for management and the cost is zero: $C\left(v_{\max }\right)=0$. The cost of stopping population spread is equal to $C(0)$. The cost function is assumed to be concave $\left(d^{2} C / d v^{2} \geq 0\right)$ because further reduction in the rate of population spread is probably more expensive than the initial reduction (Fig. 3). Among various kinds of activities that can reduce the rate of spread, some are more efficient than
FIG. 2. The length of the population front as a function of the distance from the introduction point.

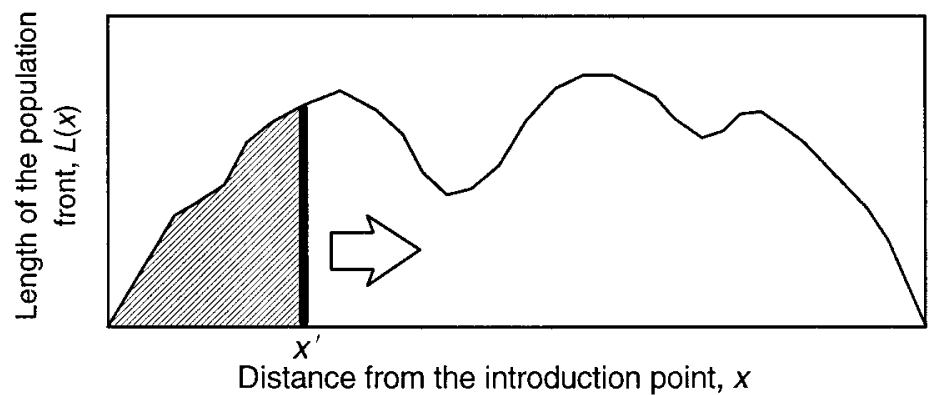




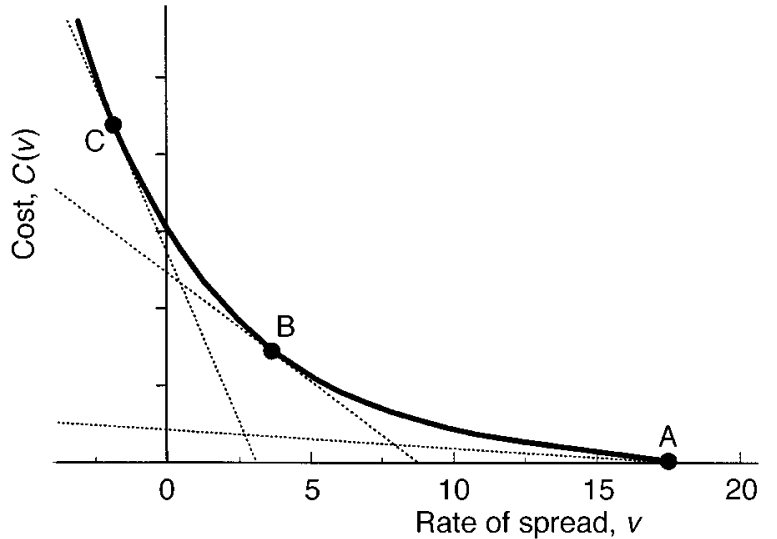

FIG. 3. Cost of the barrier zone per unit length for varying target rates of population spread. The optimal target rate of spread of the population expanding along an infinite strip is equal to the point where the tangent of function $C(v)$ is equal to $-D / \alpha$. Depending on the slope, the optimal strategy may be no management (A), slowing the spread (B), or eradication (C).

others. For a small reduction in the rate of spread, only the most efficient kinds of activities are selected; for a further reduction in the rate of spread, other less efficient kinds of activity have to be added, disproportionally increasing the cost of the entire project. Optimization is possible even without the assumption that the function $C(v)$ is concave, but this assumption simplifies the analysis considerably.

The rate of spread can be negative if pest management in the barrier zone is so intensive that the population front moves back. This may eventually result in eradication of the entire population. It seems likely that costs of moving the population front back must be greater than costs of slowing the spread.

The cost of the entire barrier zone at time $t$ is $C(v(t)) L(x(t))$. The present value of total costs (TC) for the entire project starting from current time, $t_{0}$, equals

$$
\mathrm{TC}=\int_{t_{0}}^{\infty} C(v(t)) L(x(t)) \exp \left(-\alpha\left(t-t_{0}\right)\right) d t
$$

where $\alpha$ is the discount rate.

The cost of the barrier zone depends on pest control tactics and can be estimated using optimization models. For example, Marsula and Wissel (1994) analyzed the effectiveness of a barrier zone that implemented sterile male release against the screwworm. Sharov et al. (1998) used a model to optimize the allocation of monitoring and suppression efforts in order to slow the spread of gypsy moths.

The benefits from reducing the rate of population spread result from the delay in colonization of the uninfested area compared to uncontrolled spread. These benefits are counted from the time when the population front would be expected to pass this area, in the case of uncontrolled spread, to the time when the population front actually passes. For example, at distance $x_{1}$ from

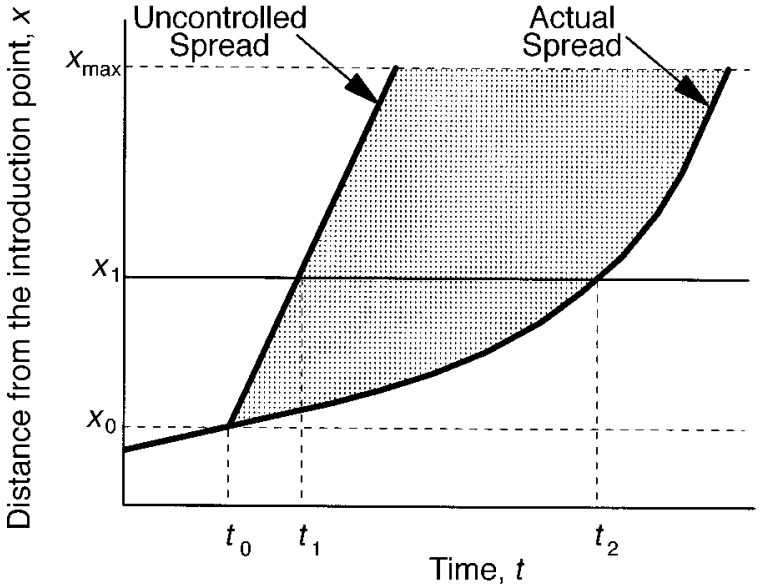

FIG. 4. Dynamics of actual (managed) and uncontrolled population spread. The shaded area is the spatiotemporal region where benefits from slowing population spread are gained; $x_{\max }$ is the most distant point in the uninfested area.

the introduction point, benefits from slowing the spread start at time $t_{1}$ and end at time $t_{2}$ (Fig. 4). The shaded area in Fig. 4 shows the spatiotemporal region where benefits from slowing population spread are gained. Thus, the present value of total benefits from slowing population spread is

$$
\mathrm{TB}=D \iint_{S} L(x) \exp \left[-\alpha\left(t-t_{0}\right)\right] d t d x
$$

where $D$ is the average damage caused by the pest per unit area per unit time, and $S$ is the shaded area in Fig. 4. It can be shown (Appendix A) that the integral (Eq. 3 ) is equal to

$$
\begin{aligned}
& \frac{D}{\alpha}\left\{\int_{x_{0}}^{x_{\max }} L(x) \exp \left[-\frac{\alpha\left(x-x_{0}\right)}{v_{\max }}\right] d x\right. \\
& \left.\quad-\int_{t_{0}}^{\infty} v(t) L(x(t)) \exp \left[-\alpha\left(t-t_{0}\right)\right] d t\right\}
\end{aligned}
$$

where $x_{\max }$ is the most distant point in the uninfested area and $x_{0}=x\left(t_{0}\right)$ is the starting location of the population front.

Combining costs and benefits (Eqs. 2 and 4), we get the present value of total net benefits

$$
\begin{aligned}
\operatorname{TNB}=\frac{D}{\alpha} \int_{x_{0}}^{x_{\max }} L(x) \exp \left[-\frac{\alpha\left(x-x_{0}\right)}{v_{\max }}\right] d x \\
-\int_{t_{0}}^{\infty}\left\{\left[\frac{D}{\alpha} v(t)+C(v(t))\right] L(x(t))\right. \\
\left.\times \exp \left[-\alpha\left(t-t_{0}\right)\right]\right\} d t .
\end{aligned}
$$

The function $x(t)$ is considered as a control function, and total net benefits, TNB, as an objective variable to 
be maximized. The first term in Eq. 5 does not depend on function $x(t)$. Thus, the optimal strategy can be found by minimizing the second term of Eq. 5. This minimum can be estimated using analytical or numerical methods, depending on the complexity of functions $L(x)$ and $C(v)$. Total net benefits (Eq. 5) may have several local maxima. For example, there may be one maximum for pest eradication and a second maximum for slowing or stopping population spread. In the case of several maxima, it is necessary to select the highest one, which corresponds to the optimal management strategy.

\section{Special Cases}

In this section, we determine the best strategies for managing the rate of population spread to maximize the present value of total net benefits (Eq. 5) in three special cases. First, we consider a population that expands its range along an infinite strip with a constant width. We then consider population spread in a rectangular area with the population front parallel to the side of the rectangle. Finally, we analyze the spread of a recently established population with a circular range that expands in all directions.

\section{Population expansion along an infinite strip}

The length of the population front, $L$, is a constant because it is equal to the width of the strip. The optimal rate of spread is also constant because all conditions remain uniform as the population front progresses along the strip. Then, the second term in Eq. 5 has a minimum if the expression $[D v / \alpha+C(v)]$ is minimal, i.e., if

$$
\frac{d C(v)}{d v}=-\frac{D}{\alpha} .
$$

This means that the optimal target rate of spread, $v$, corresponds to the point at which the tangent of function $C(v)$ is equal to the slope, $-D / \alpha$ (Fig. 3). If the slope is small $\left(-D / \alpha \geq d C\left(v_{\max }\right) / d v\right)$, then $v=v_{\max }$, indicating that the best strategy is no management (Fig. $3 \mathrm{~A})$. If the slope is intermediate $(d C(0) / d v<-D / \alpha<$ $\left.d C\left(v_{\max }\right) / d v\right)$, then $0<v<v_{\max }$, indicating that slowing the spread is the optimal strategy (Fig. 3B). Finally, if the slope is steep $(-D / \alpha<d C(0) / d v)$, then $v<0$, indicating that the population front should be moved back, i.e., eradicated (Fig. 3C). Because the cost function is assumed to be concave, its derivative, $d C / d v$, increases with increasing $v$. Thus, the optimal rate of spread, $v$, is increasing with decreasing damage, $D$, caused by the pest, and increasing discount rate, $\alpha$.

The present value of total net benefits (Eq. 5) obtained from optimally managing population spread is

$$
\mathrm{TNB}=\frac{L}{\alpha^{2}}\left[D\left(v_{\max }-v\right)-\alpha C(v)\right]
$$

where $v$ is the optimal rate of spread, which is the solution of Eq. 6.
Natural populations always have limits to their expansion, contrary to our assumption of infinite spread. However, if the uninfested zone is long enough, then Eq. 6 might yield a good approximation for the optimal target rate of spread. For example, if the annual discount rate is 0.05 , then net benefits obtained after 60 yr would have a negligibly small contribution to the present value (Eq. 1). Thus, it is unimportant whether the population will reach the end of the uninfested area after $60 \mathrm{yr}$.

\section{Spread in a rectangular area}

In this example, the population front moves from one side of the rectangle to the opposite side, and its progression is measured by distance $x$, which changes from 0 to $x_{\max }$. The length of the population front, $L(x)$, remains constant $(=L)$ in the interval $0 \leq x \leq x_{\max }$.

The optimal rate of managed population spread in the rectangular area depends on the location of the front, $x$, and can be estimated using the Euler equation (Elsgolts 1962). Mathematical details can be found in Appendix B, and here we will only summarize the results. There may be either one or two local maxima of total net benefits at each location $x$ that correspond either to slowing of population spread $(v>0)$ or to eradication $(v<0)$. These maxima correspond to two lines in Fig. 5: the upper line represents slowing the spread and the lower line represents eradication. The stationary rate of spread, $v^{*}$, which is the solution of Eq. 6, is the asymptote for one of these lines. These lines are solutions of the differential equation B.4 in Appendix B that correspond to specific boundary conditions (Eqs. B.6 and B.7). If Eq. B.7 has no solution $v<\min \left(0, v^{*}\right)$, eradication should be completed in one step if it is attempted.

If the population front is currently located at distance $x_{0}$, then the optimal strategy of managing population spread is determined as follows. If there is only one local maximum of total net benefits at distance $x_{0}$ (one line in Fig. 5), then this strategy is optimal. If two local maxima exist at distance $x_{0}$, then it is necessary to determine which of them is a global maximum that yields highest total net benefits (estimated using Eq. $5)$. The management strategy that corresponds to the global maximum is optimal. At distance $x_{1}$ from the introduction point, total net benefits from eradication and from slowing the spread are equal (Fig. 5). If the population front has not reached distance $x_{1}$, then eradication is the optimal strategy because it corresponds to the global maximum of total net benefits. However, if the population front has already passed distance $x_{1}$, then slowing the spread is the optimal strategy.

As the population front progresses, the benefits from eradication decrease faster than the benefits from slowing the spread; thus, it becomes more likely that slowing the spread will yield higher benefits than eradication. When the population front approaches the end of the potential range, slowing the spread should be aban- 


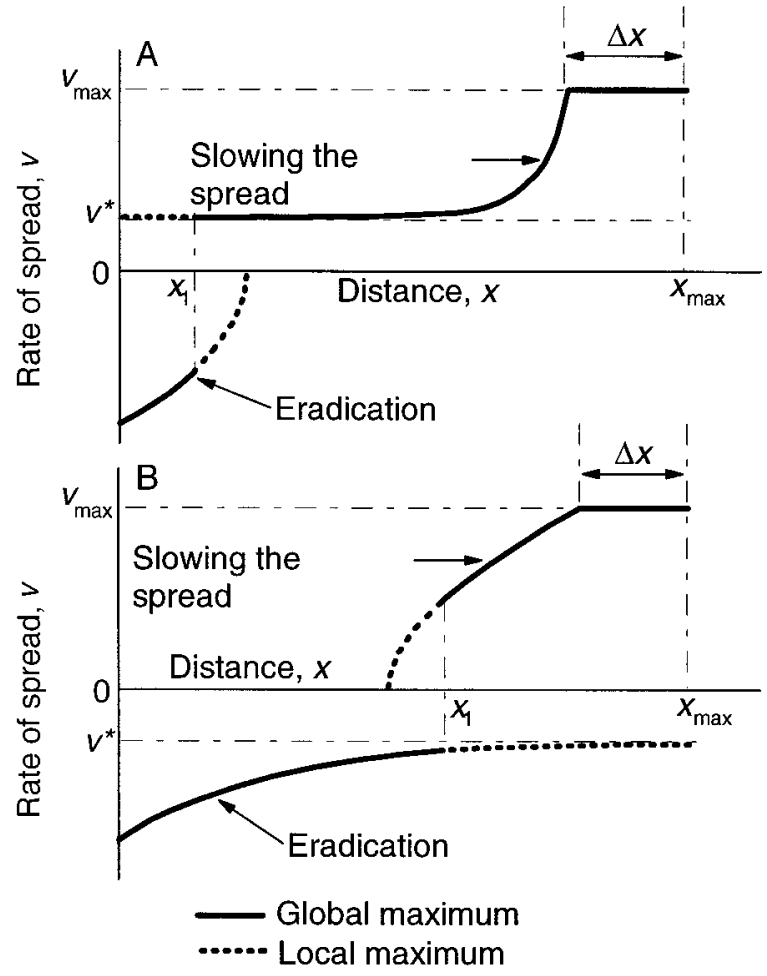

FIG. 5. Optimal management of the rate of population spread, $v$, in a rectangular area; $v^{*}$ is the solution of Eq. 6 $v_{\max }$ is the rate of unmanaged spread, and $\Delta x$ is the distance defined by the boundary condition (Eq. B.6). Graphs (A) and (B) correspond to $v^{*}>0$ and $v^{*}<0$, respectively. The global maximum corresponds to a strategy that yields the highest net benefits (benefits are not shown in this graph). The local maximum corresponds to a strategy yielding net benefits that are higher than for any small variation of this strategy, but the local maximum is lower than the global maximum.

doned because net benefits become zero. If management costs are high relative to the damage caused by the pest species, then slowing the spread is more likely to be the optimal strategy than eradication, except at the initial stages of invasion (Fig. 5A). If management costs are low and damage is high, however, then eradication may be optimal even if the population has occupied most of its potential range (Fig. 5B) or even the entire range. Stopping the spread is never an optimal strategy. It may yield positive total net benefits, but these benefits are always smaller than the benefits obtained from either eradicating or slowing the spread of the population.

\section{Spread of small populations}

The major limitation of the previous special case is that we did not consider the increase in length of the population front during the initial period of introduction. Thus, it cannot be used for optimizing the eradication of small initial colonies. In order to optimize the management of small colonies, we will assume that the population was introduced in the center of the potential species range. (Fig. 1A). Thus, the length of the population front increases linearly with increasing distance from the introduction point,

$$
L(x)=2 \pi x .
$$

To find optimal strategies of eradicating or slowing the spread, it is again possible to use the Euler equation. However, the analysis becomes even more complicated than in the previous special case, and requires several simplifying assumptions. First, we assume that eradication is always done in one step, which is reasonable for small colonies, and that eradication costs are proportional to the area of the colony. Second, if the option of slowing the spread is selected, we assume that the target rate of spread, $v$, is equal to the stationary rate of spread, $v^{*}$, which is the solution of Eq. 6. This rate is usually close enough to the optimal rate, except when the radius of the colony is either very small or so large that the population occupies nearly the entire potential range. Thus, net benefits from keeping the rate of spread $v=v^{*}$ are close to net benefits from the optimized strategy of slowing the spread.

Now we can compare total net benefits from eradication vs. slowing the spread. The strategy that yields higher total net benefits should be recommended. The present value of total net benefits obtained from eradication is estimated assuming that all costs are paid at present time:

$$
\operatorname{TNB}_{\mathrm{E}}(x)=\frac{2 \pi D F\left(x, v_{\max }\right)}{\alpha^{3}}-\pi x^{2} E
$$

where $x$ is the initial radius of the infestation; $E$ is the cost of eradication per square kilometer; and $v_{\max }$ is the rate of uncontrolled spread. The first term in Eq. 9 represents benefits (Eq. 3) and the second term represent costs (Eq. 2). The function $F$ in Eq. 9 is

$$
F(x, v)=v^{2}+\alpha v x+0.5(\alpha x)^{2}-v G(x, v)
$$

and the function $G$ is

$$
G(x, v)=\left(v+\alpha x_{\max }\right) \exp \left[-\alpha\left(x_{\max }-x\right) / v\right]
$$

where $x_{\max }$ is the radius of the potential species range.

Total net benefits associated with slowing the spread are equal to

$$
\begin{aligned}
\operatorname{TNB}_{\mathrm{S}}(x)= & \frac{2 \pi D\left[F\left(x, v_{\text {max }}\right)-F(x, v)\right]}{\alpha^{3}} \\
& -\frac{2 \pi C(v)}{\alpha^{2}}[G(x, v)+\alpha x+v]
\end{aligned}
$$

where $v=v^{*}$ is the solution of Eq. 6, and functions $F$ and $G$ are specified by Eqs. 10-11. The first term in Eq. 12 represents benefits (Eq. 3) and the second term represents costs (Eq. 2).

The values of total net benefits obtained from eradication (Eq. 9) and slowing the spread (Eq. 12) can be compared for varying radii, $x$, of the initial infestation. The largest population that could be eradicated has the radius, $x$, at which total net benefits from eradication 


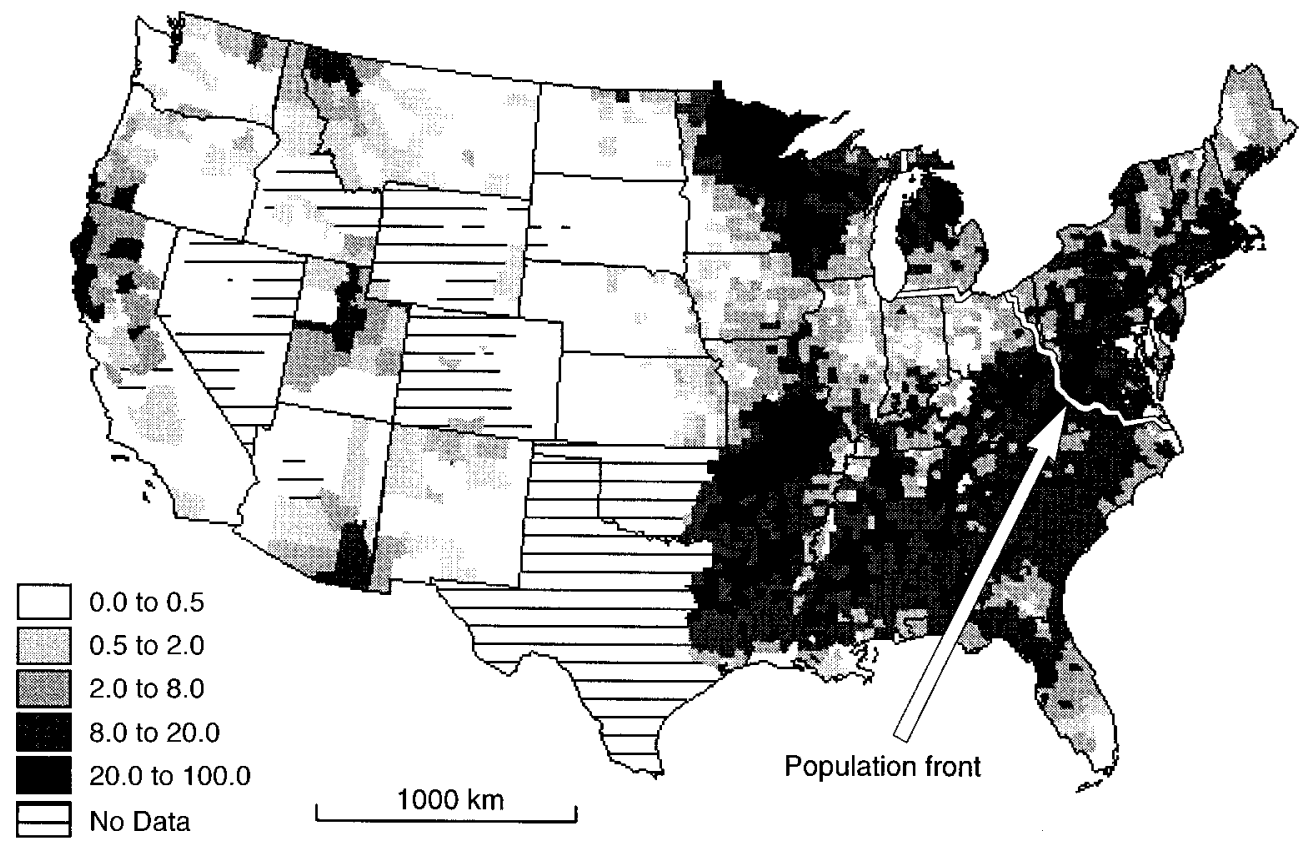

FIG. 6. Percentage of the land area in which $>50 \%$ of the basal area is of tree species preferred by the gypsy moth (modified from Liebhold et al. 1997), and the front of gypsy moth populations in 1995.

and slowing the spread are the same: $\operatorname{TNB}_{\mathrm{E}}(x)=$ $\operatorname{TNB}_{\mathrm{S}}(x)$.

\section{Case Study: Managing Gypsy Moth Spread in NORTH AMERICA}

The gypsy moth, Lymantria dispar, was accidentally introduced to North America near Boston in 1869 and has been slowly expanding its range since then (Liebhold et al. 1989). McFadden and McManus (1991) and Liebhold et al. (1992) suggested that transportation of gypsy moth egg masses and other life stages by humans is probably the most important dispersal mechanism that leads to the expansion of its range.

The rate of spread was relatively high $(9.45 \mathrm{~km} / \mathrm{yr})$ from 1900 to 1915 , then very low $(2.82 \mathrm{~km} / \mathrm{yr})$ from 1916 to 1965 , and increased to $20.78 \mathrm{~km} / \mathrm{yr}$ from 1966 to 1990 in counties where the mean minimum January temperature was $>-13.9^{\circ} \mathrm{C}\left(>7^{\circ} \mathrm{F}\right.$; corrected from Liebhold et al. 1992). Low spread rates in 1916-1965 may have resulted from several attempts to stop the spread of gypsy moths using barrier zones. The most important of these was a barrier zone established in 1923 from Canada to Long Island along the Hudson River Valley (McFadden and McManus 1991), which was used until 1941, when the area finally became infested.

Currently, the U.S. Department of Agriculture Forest Service is conducting the Slow-the-Spread (STS) pilot project to evaluate the feasibility of slowing the gypsy moth spread in specific portions of North Carolina, Virginia, West Virginia, and Michigan (McFadden and McManus 1991, Leonard and Sharov 1995, Leuschner et al. 1996). In project areas, thousands of pheromone- baited traps (Schwalbe 1981) are placed annually in 2$\mathrm{km}$ and $0.5-\mathrm{km}$ grids to detect and delineate isolated colonies located immediately beyond the expanding population front. Subsequent eradication (or suppression) of these colonies appears to have resulted in a decrease in the rate of population spread (Sharov et al. 1996). Sharov and Liebhold (1998a) developed a metapopulation model of species range expansion that predicted that the project would result in a $54.3 \%$ decrease in the rate of gyspy moth spread. The actual reduction in the rate of spread in the Appalachian Mountains was $59 \%$, which is close to predicted value.

Liebhold et al. (1997) plotted a map of host plant availability for the gypsy moth (Fig. 6), indicating that the gypsy moth occupies about one-third of its potential range at the present time. The area that can potentially support gypsy moth populations is distinctly subdivided into two portions: the northern region (Michigan, Wisconsin, and Minnesota) and the southern region (to the south from Iowa, Illinois, and Indiana). The gypsy moth will probably spread independently in these two regions. In this analysis, we consider only the southern region, because most activities in the STS project were performed in this area. We assume that the length of the population front $L$ is $1000 \mathrm{~km}$, which is the approximate distance from Lake Erie to the ocean shore between North Carolina and South Carolina. The gypsy moth has already spread $\sim 1000 \mathrm{~km}$ from the point of introduction (Boston, Massachusetts), and the depth of the potential range that remains uninfested is $\sim 1500$ $\mathrm{km}$ (Fig. 6). Thus, $x_{\max }=2500 \mathrm{~km}$. The rate of uncontrolled spread, $v_{\max }$, is $21 \mathrm{~km} / \mathrm{yr}$ (Liebhold et al. 1992). 
Row et al. (1981) recommended using a discount rate of $0.04 / y r$. However, it may be necessary to increase the discount rate because of the uncertainty in model parameters. The error in model predictions tends to increase with time. If the discount rate is small, the present value of total benefits, TNB, is sensitive to benefits in the far future, which are predicted with substantial error. As a result, the error of the TNB value becomes large, and decisions based on the model may have a high risk. Thus, we will use two discount rate values: $\alpha=0.04$ and $\alpha=0.1$. The second value is more conservative, because the risks associated with uncertainty of predictions are smaller. The higher discount rate $(\alpha=0.1)$ is one at which decisions are based on short-term economics.

Sharov et al. (1998) used a model to estimate the costs of slowing the spread of gypsy moth populations in the central Appalachian Mountains. This model generated values of the function $C(v)$ for $v=5,9,13$, and $17 \mathrm{~km} / \mathrm{yr}$. The model of Sharov et al. (1998) is not appropriate for negative and small positive target spread rates (e.g., $<5 \mathrm{~km} / \mathrm{yr}$ ). It considers detection and eradication of isolated colonies only; if the target spread rate is $<5 \mathrm{~km} / \mathrm{yr}$, it may be necessary to treat large areas of continuously distributed gypsy moth populations.

The cost of management of a barrier zone with negative and small positive target rates can be evaluated using the following assumptions. The model of Sharov and Colbert (1996) predicts that eradication of a gypsy moth population with initial density of $10^{5} \mathrm{eggs} / \mathrm{ha}$ ( $\sim 200$ egg masses/ha) requires $4 \mathrm{yr}$ of treatment, assuming no density dependence in gypsy moth mortality at low densities. Defoliating populations $(>30 \%$ defoliation) are characterized by a density of $>4 \times 10^{5}$ eggs/ha (Liebhold et al. 1993); therefore, $\geq 1$ yr more is necessary to reduce the density to $10^{5} \mathrm{eggs} / \mathrm{ha}$. Thus, we can take $5 \mathrm{yr}$ as the period required for eradicating high-density populations.

Chemical and even bacterial pesticides cannot be used over large, continuous areas $\left(\sim 10^{7} \mathrm{ha}\right)$ because of possible adverse effects on nontarget organisms. Only species-specific treatments, such as viruses (nuclear polyhedrosis virus, NPV), pheromones, or sterile insect releases, can be applied. Average treatment costs in the STS project in 1994-1995 were \$25 per acre, or per 0.4 ha (J. Mayo, Clemson University, South Carolina, personal communication). Then, the approximate cost of 5 years of treatments is $\$ 31000 / \mathrm{km}^{2}$. Liebhold et al. (1992) predicted, using the model of Skellam (1951), that the range of the gypsy moth would expand by $2.5 \mathrm{~km} / \mathrm{yr}$ due to larval dispersal, even if there were no long-distance transportation of its egg masses and other life stages. We assume that the population spreads forward by $3 \mathrm{~km} / \mathrm{yr}$ even if all isolated colonies are eradicated. Thus, the cost of $1 \mathrm{~km}$ length of the barrier zone would be

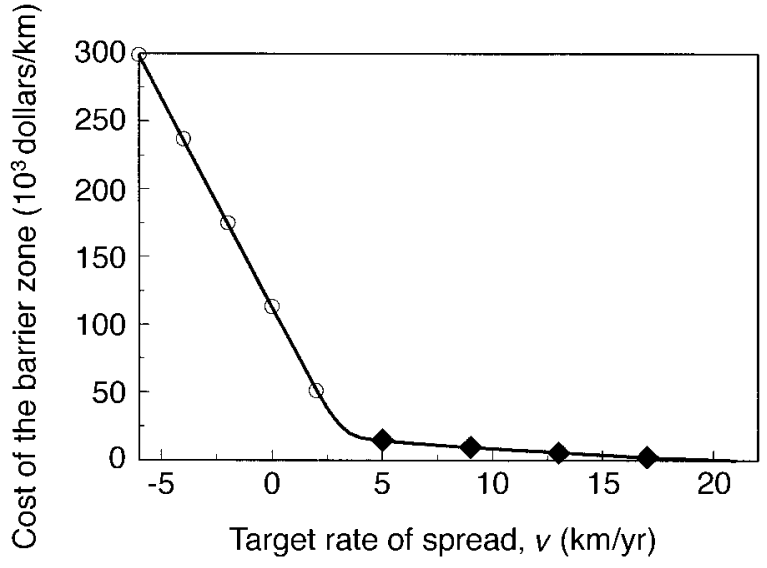

FIG. 7. Expected cost of the barrier zone per $1 \mathrm{~km}$ length for various target rates of gypsy moth spread. The line is fitted from Eq. 14; $\downarrow$ represents the model of Sharov et al. (1998); $\bigcirc$ represents Eq. 13.

$$
C(v)=c_{1}(3-v)+c_{2}
$$

where $c_{1}=\$ 31000$ (eradication costs per square kilometer) in the generally infested area, and $c_{2}$ are expected costs of eradicating isolated colonies per $1 \mathrm{~km}$ length of the population front. According to Eq. 13, $C(3)=c_{2}$. The model of Sharov et al. (1998) predicted that $C(5)=\$ 14880 / \mathrm{km}$ of the population front. Because $C(3)>C(5)$ (note that $C(v)$ is a decreasing function), we expect that the value of $C(3)$ and, hence, $c_{2}$, is $\sim \$ 20000$. For convenience, we used a smooth cost function that approximated both the cost of slowing the spread and hypothetical costs of eradication (Fig. 7):

$$
C(v)=b_{0}+b_{1} v+b_{2} \sqrt{v^{2}+b_{3} v+b_{4}}
$$

where parameters $b_{0}=64150 ; b_{1}=-16040 ; b_{2}=$ $15200 ; b_{3}=-6.15$; and $b_{4}=10$ were found by least square fitting.

Annual damages caused by gypsy moth populations per unit area, $D$, can be estimated using the economic model of Leuschner et al. (1996). According to these authors, the present value of negative impacts of gypsy moth spread over the next $25 \mathrm{yr}$ in the United States, excluding Michigan and Wisconsin, is \$3798.9 million (assuming the rate of spread of $20.1 \mathrm{~km} / \mathrm{yr}$ ). Thus,

$$
\sum_{t=0}^{25} D L v t \exp (-\alpha t)=3798.9 \times 10^{6} .
$$

Solving this equation with $L=1000$ and $\alpha=0.04$, we get $D=\$ 1120$ per square kilometer per year. We believe that the value of negative impacts caused by the gypsy moth was overestimated by Leuschner et al. (1996), because they assumed that residential impacts, which are $\sim 83 \%$ of the total impacts, occur every year in the entire area. In reality, residential impacts occur only in areas defoliated by the gypsy moth. In the generally infested zone in Virginia and West Virginia, the percentage of area defoliated in 1990-1994 varied from 

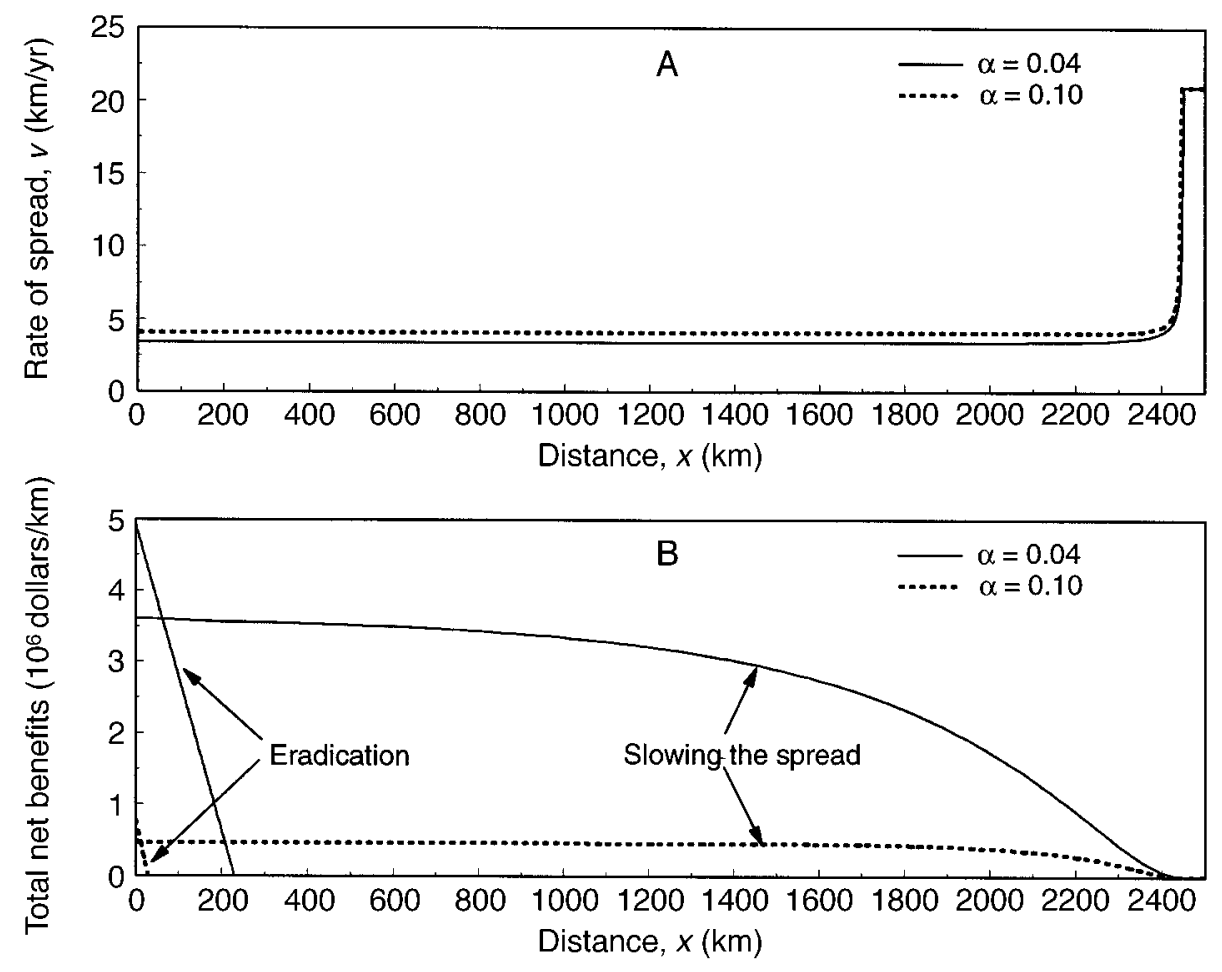

FIG. 8. (A) The optimal target rate of gypsy moth spread, and (B) economic benefits (present value) per $1 \mathrm{~km}$ length of the population front that result from either slowing population spread or one-step eradication, predicted by the model that assumes population spread in a rectangular potential range starting at varying distances, $x$, from one side; $\alpha$ is the discount rate.

$18 \%$ to $34 \%$, being $21 \%$ on average (A. A. Sharov and A. M. Liebhold, unpublished data). Thus, we assume that residential impacts were one-fifth those estimated by Leuschner et al. (1996). This results in a damage estimate of $D=\$ 380 \cdot \mathrm{km}^{-2} \cdot \mathrm{yr}^{-1}$.

According to Eq. B.6 in Appendix B, slowing the rate of gypsy moth spread is economically beneficial up to $49 \mathrm{~km}$ from the end of the potential species range for $\alpha=0.04$ and $53 \mathrm{~km}$ for $\alpha=0.1$. The optimal target rate of slowing gypsy moth spread remains almost constant and close to the stationary rate of spread, $v^{*}$, until the distance from the population front to the end of the uninfested area $(x=2500 \mathrm{~km})$ becomes $<200 \mathrm{~km}$ (Fig. $8 \mathrm{~A}$ ). This stationary rate of spread, which is the solution of Eq. 6, equals $3.43 \mathrm{~km} / \mathrm{yr}$ for $\alpha=0.04$ and $4.08 \mathrm{~km} / \mathrm{yr}$ for $\alpha=0.1$.

In the Appalachian Mountains, the STS project has resulted in a reduction in the rate of gypsy moth spread from $21 \mathrm{~km} / \mathrm{yr}$ to $8.6 \mathrm{~km} / \mathrm{yr}$ (Sharov and Liebhold $1998 b)$. According to the model, the optimal target rate of spread is $<8.6 \mathrm{~km} / \mathrm{yr}$ (Fig. $8 \mathrm{~A}$ ). Let us compare benefits from a suboptimal strategy used in the STS program, assuming that it would continue until the entire potential range is occupied, with potential benefits from using the optimal target rate of spread shown in Fig. 8A. If $v=8.6 \mathrm{~km} / \mathrm{yr}$, then the expected present value of total net benefits would be $\$ 2387000 / \mathrm{km}$ for $\alpha=0.04$ and $\$ 361000 / \mathrm{km}$ for $\alpha=0.1$. The present value of total net benefits from using the optimal target rate of spread is $\$ 3340000 / \mathrm{km}$ of the population front for $\alpha=0.04$, or $\$ 461000 / \mathrm{km}$ for $\alpha=0.1$ (Fig. 8B; $x$ $=1000 \mathrm{~km}$ ). Thus, the model predicts that additional value of $28-40 \%$ can be obtained from further reduction of gypsy moth spread by increased management activity in the barrier zone.

Equation B.7 in Appendix B has no solution, indicating that eradication of the gypsy moth population in one step is more beneficial than the gradual backward movement of the barrier zone. Benefits from eradication are greater than benefits from slowing the spread only at the initial stages of invasion, when the population front has extended by $<62 \mathrm{~km}$ for $\alpha=0.04$ and $<16 \mathrm{~km}$ for $\alpha=0.1$ (Fig. 8B).

The model of spread of small populations (case 3 ) gives more accurate estimates of the size of colonies that can be eradicated. We assumed that a small colony became established in the center of the potential range. All parameter values are the same as those previously used, except $x_{\max }=1250 \mathrm{~km}$ (half of the size of the uninfested area), because a colony expands from the center rather than moving from one side of the area to another. As a result, the population front extends only by half of the distance to reach the end of the uninfested area (for simplicity, we ignored the expansion of the generally infested area). The cost of eradication is $E$ $=\$ 31000 / \mathrm{km}^{2}$. 


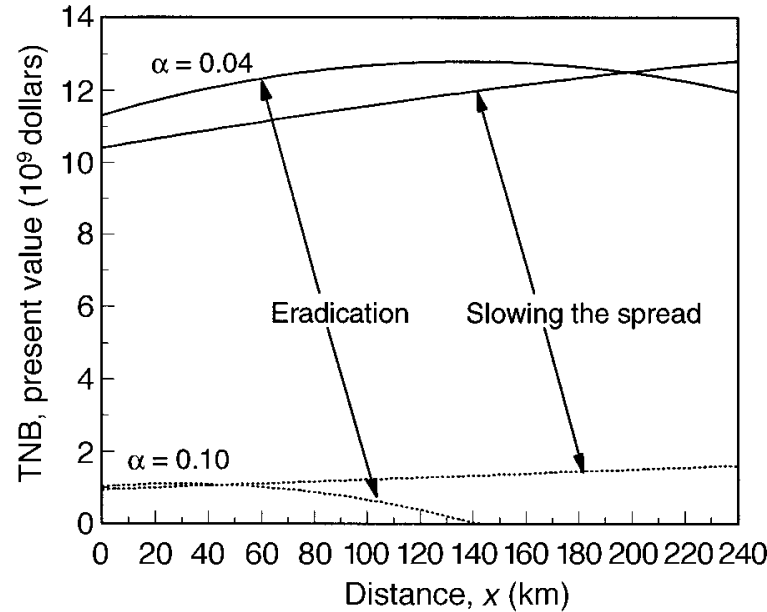

FIG. 9. Total net economic benefits (TNB) from either slowing the spread or doing a one-step eradication of a circular gypsy moth population of radius $x ; \alpha$ is the discount rate.

According to the model, one-step eradication of a small gypsy moth colony yields slightly higher total net benefits (Eq. 12) than does slowing the population spread (Eq. 9) when the size of the colony is small: $x$ $<195 \mathrm{~km}$ for $\alpha=0.04$, and $x<45 \mathrm{~km}$ for $\alpha=0.1$ (Fig. 9). Thus, the maximum radius of a colony that it would beneficial to eradicate was estimated as 45-195 $\mathrm{km}$, depending on the discount rate. For larger colonies, the model recommends slowing the spread as a management strategy.

Results obtained in this section should be considered preliminary because of uncertainty in several model parameters. Estimates of damages caused by the gypsy moth and the cost of the barrier zone at target spread rates of $<5 \mathrm{~km} / \mathrm{yr}$ are the least certain.

\section{Discussion}

This study demonstrates the value of bioeconomic analysis in planning programs that implement barrier zones for managing the spread of pest species. A barrier zone is a tool for total population management (TPM), as advocated by Knipling (1966). The target of the TPM is the entire population, whereas IPM is usually targeted at local populations. The term TPM has not been widely used, because Knipling (1966) overemphasized eradication as the major goal. Now the term "areawide pest management" (Klassen 1996) essentially expresses the same idea, except that it does not consider eradication as a panacea.

Our model specifies optimal strategies for population containment and eradication. This analysis helps to avoid suboptimal decisions based on intuition. For example, Dahlsten et al. (1989: 11) stated that "insects that have already colonized parts of the United States, or any large land mass or continent, probably should not be the targets for eradication programs in other sections of the country because of their potential for recolonization." Our analysis clearly demonstrates that this statement is wrong. Eradication of small, isolated colonies of the gypsy moth within barrier zones is not only feasible, but also economically justified because the model predicts positive net benefits under realistic assumptions.

The model shows that eradication can be successfully implemented mainly against a recently established species whose range is limited. Only in rare cases, such as that of the screwworm, is eradication so inexpensive and environmentally safe that it can be applied to large populations. Of course, as speciesspecific pest control agents become less expensive, greater numbers of species can be successfully eradicated over large areas. The economics of many eradication programs were never thoroughly evaluated. For example, the boll weevil eradication project has continued since 1977 (Coppedge 1996), but only partial success has been achieved. If chemical pesticides are used in eradication programs, it is necessary to account for side effects on nontarget species. For example, intensive pesticide treatments against the boll weevil in Texas suppressed natural enemies and, as a result, serious outbreaks of secondary pests occurred (Coppedge 1996).

Slowing population spread is a relatively new tool in pest management. It was not seriously considered before, because of the emphasis on eradication or stopping the spread of exotic pests. Our model demonstrates that considerable benefits from slowing population spread may exist even if only a small portion of potential range remains uninfested. In the case of the gypsy moth, the reduction of the spread rate is achieved by eradicating small, isolated colonies beyond the expanding population front. Because these colonies are usually small, treatment can be confined to small patches; thus, the program has a very limited impact on nontarget organisms.

An unexpected result of our analysis is that stopping population spread in a rectangular area is not an optimal strategy. Stopping the spread may be optimal only if a natural barrier exists that creates a "bottleneck" in the middle of function $L(x)$ (as in Fig. 2), because the cost of the barrier zone can decrease substantially if it coincides with the natural barrier.

Our model can be a prototype for more detailed, specific models to be used as guides for management of particular pest populations. In these specific models, the function $L(x)$ may have a more complicated shape than in the theoretical cases we have discussed, and model parameters (e.g., the maximal rate of spread and management costs) may depend on local conditions, such as terrain, vegetation, and climate. Numerical optimization (e.g., dynamic programming) may be a better optimization tool for these models than is the Euler equation (Elsgolts 1962; Appendix B).

Control of natural resources may depend considerably on social factors; thus, the model presented in this 
paper cannot automatically generate decisions. Rather, it provides information on the economic viability of barrier zone projects that may affect decisions in a political arena (LeVeen 1989). Large-scale pest management projects are usually expensive and, thus, are affected by budget constraints. For example, it may be optimal, in theory, to eradicate the pest population in one step, but this may require more funds than are available. Shifting funds from other programs may cause more damage to these programs than potential gains from the eradication program. The compromise may be reached by extending the eradication project over a longer period. Our bioeconomic model can be used to estimate the difference in total net benefits between the optimal and suboptimal strategy. Then, a decision can be made if the program is still viable under current financial constraints. Even if the program is already in an operational stage, it still can be affected by unforeseen social or environmental factors. If a more serious pest species becomes established in the country, then it may be necessary to move a portion of funds to manage this new species.

\section{ACKNOWLEDGMENTS}

We thank Peter Turchin (University of Connecticut, Storrs) and David Williams (U.S. Forest Service, Radnor, Pennsylvania) for discussion of the manuscript. This research was funded by Grant Number 95-37313-1892 from the USDA Cooperative State Research, Education, and Extension Service.

\section{Literature Cited}

Allen, P. G., L. W. Botsford, A. M. Schuur, and W. E. Johnston. 1984. Bioeconomics of aquaculture. Elsevier, Amsterdam, The Netherlands.

Clark, C. W. 1976. Mathematical bioeconomics. The optimal management of renewable resources. Wiley, New York, New York, USA.

Coppedge, J. R. 1996. Eradication of the boll weevil in the United States through an areawide approach. Proceedings of the International Congress of Entomology XX:704. Firenze, Italy, 25-31 August 1996.

Dahlsten D. L., R. Garcia, and H. Lorraine. 1989. Eradication as a pest management tool: concepts and contexts. Pages 3-15 in D. L. Dahlsten and R. Garcia, editors. Eradication of exotic pests. Analysis with case histories. Yale University Press, New Haven, Connecticut, USA.

Elsgolts, L. E. 1962. Calculus of variations. Pergamon Press, London, UK.

Goh, B. S. 1980. Management and analysis of biological populations. Elsevier, Amsterdam, The Netherlands.

Gutierrez, A. P., and Y. H. Wang. 1984. Models for managing the economic impact of pest populations in agricultural crops. Pages 729-761 in C. B. Huffaker and R. L. Rabb, editors. Ecological entomology. Wiley, New York, New York, USA.

Hall, F. R. 1974. Bioeconomics of apple pests: cost appraisal of crop injury data. Journal of Economic Entomology 67: 517-521.

Hastings, A. 1996. Models of spatial spread: is the theory complete? Ecology 77:1675-1679.

Isaev, A. S., R. G. Khlebopros, L. V. Nedorezov, Y. P. Kondakov, and V. V. Kiselev. 1984. Dynamics of numbers of forest insects. Nauka Publishing House, Siberian Division, Novosibirsk, Russia (in Russian).

Klassen, W. 1996. Area-wide pest management: conceptual, theoretical, and historical framework. Proceedings of the International Congress of Entomology XX:704. Firenze, Italy, 25-31 August 1996.

Knipling, E. F. 1966. Some basic principles in insect population suppression. Bulletin of the Entomological Society of America 12:7-15.

Leonard, D. S., and A. A. Sharov. 1995. Slow the Spread project update: developing a process for evaluation. Pages 82-85 in Proceedings of the USDA Interagency Gypsy Moth Research Forum. U.S. Forest Service General Technical Report NE-213.

Leuschner, W. A., and P. Berck. 1985. Impacts on forest uses and values. Pages 105-120 in W. E. Waters, R. W. Stark, and D. L. Wood, editors. Integrated pest management in pine-bark beetle ecosystems. Wiley, New York, New York, USA.

Leuschner, W. A., J. A. Young, S. A. Walden, and F. W. Ravlin. 1996. Potential benefits of slowing the gypsy moth's spread. Southern Journal of Applied Forestry 20: 65-73.

LeVeen, E. P. 1989. Economic evaluation of eradication programs. Pages 41-56 in D. L. Dahlsten and R. Garcia, editors. Eradication of exotic pests. Yale University Press, New Haven, Connecticut, USA.

Liebhold, A. M., K. W. Gottschalk, D. A. Mason, and R. R. Bush. 1997. Forest susceptibility to the gypsy moth. Journal of Forestry 95:20-24.

Liebhold, A. M., J. A. Halverson, and G. A. Elmes. 1992. Gypsy moth invasion in North America: a quantitative analysis. Journal of Biogeography 19:513-520.

Liebhold, A. M., W. L. Macdonald, D. Bergdahl, and V. C. Mastro. 1995. Invasion by exotic forest pests: a threat to forest ecosystems. Forest Science Monographs 30. Bethesda, Maryland, USA.

Liebhold, A. M., V. Mastro, and P. W. Schaefer. 1989. Learning from the legacy of Leopold Trouvelot. Bulletin of the Entomological Society of America 35:20-21.

Liebhold, A. M., E. E. Simons, A. Sior, and J. D. Unger. 1993. Forecasting defoliation caused by the gypsy moth from field measurements. Environmental Entomology 22: 26-32.

Marsula, R., and C. Wissel. 1994. Insect pest control by a spatial barrier. Ecological Modelling 75/76:203-211.

McFadden, M. W., and M. E. McManus. 1991. An insect out of control? The potential for spread and establishment of the gypsy moth in new forest areas in the United States. Pages 172-186 in Y. N. Baranchikov, W. J. Mattson, F. P. Hain, and T. L. Payne, editors. Forest insect guilds: patterns of interaction with host trees. U.S. Forest Service General Technical Report NE-153.

Pedigo, L. P. 1985. Integrated pest management. Pages 22 31 in McGraw-Hill yearbook of science and technology 1985. McGraw-Hill, New York, New York, USA.

Pimentel, D. 1986. Biological invasions of plants and animals in agriculture and forestry. Pages 149-162 in H. A. Mooney and J. A. Drake, editors. Ecology of biological invasions of North America and Hawaii. Ecological studies 58. Springer-Verlag, New York, New York, USA.

Plant, R. E., M. Mangel, and L. E. Flynn. 1985. Multiseasonal management of agricultural pests. II. The economic optimization problem. Journal of Environmental Economics and Management 12:45-61.

Row, C., H. F. Kaiser, and J. Sessions. 1981. Discount rate for long-term Forest Service investments. Journal of Forestry 79:367-369.

Sailer, R. I. 1983. History of insect introductions. Pages 1538 in C. L. Wilson and C. L. Graham, editors. Exotic plant pests and North American agriculture. Academic Press, New York, New York, USA.

Schwalbe, C. P. 1981. Disparlure baited traps for survey and 
detection. Pages 542-548 in C. C. Doane and M. L. McManus, editors. The gypsy moth: research toward integrated pest management. U.S. Department of Agriculture Technical Bulletin 1584 .

Sharov, A. A., and J. J. Colbert. 1996. A model for testing hypotheses of gypsy moth, Lymantria dispar L., population dynamics. Ecological Modelling 84:31-51.

Sharov, A. A., and A. M. Liebhold. 1998a. Model of slowing the population spread with a barrier zone. Ecological Applications, in press.

Sharov, A. A., and A. M. Liebhold. 1998b. Quantitative analysis of gypsy moth spread in the Central Appalachians. In J. Braumgartner, P. Brandmayer, and B. F. J. Manly, editors. Population and community ecology for insect management and conservation. Balkema, Rotterdam. The Netherlands, in press.

Sharov, A. A., A. M. Liebhold, and E. A. Roberts. 1996 Spread of gypsy moth (Lepidoptera: Lymantriidae) in the Central Appalachians: comparison of population boundaries obtained from male moth capture, egg mass counts, and defoliation records. Environmental Entomology 25: 783-792.

Sharov, A. A., A. M. Liebhold, and E. A. Roberts. 1998.
Optimizing the use of barrier zones to slow the spread of gypsy moth (Lepidoptera: Lymantriidae) in North America. Journal of Economic Entomology 91:165-174.

Shigesada, N., K. Kawasaki, and Y. Takeda. 1995. Modeling stratified diffusion in biological invasions. American Naturalist 146:229-251.

Shoemaker, C. A., and D. W. Onstad. 1983. Optimization analysis of the integration of biological, cultural, and chemical control of alfalfa weevil (Coleoptera: Curculionidae). Environmental Entomology 12:286-295.

Simberloff, D. 1986. Introduced insects: a biogeographic and systematic perspective. Pages 3-26 in H. A. Mooney and J. A. Drake, editors. Ecology of biological invasions of North America and Hawaii. Ecological studies 58. Springer-Verlag, New York, New York, USA.

Skellam, J. G. 1951. Random dispersal in theoretical populations. Biometrika 38:196-218.

Stern, V. M. 1975. The bioeconomics of pest control. Iowa State Journal of Research 49:467-472.

Stern, V. M., R. F. Smith, R. van den Bosch, and K. S. Hagen. 1959. The integrated control concept. Hilgardia 29:81101.

Turchin, P., and A. D. Taylor. 1992. Complex dynamics in ecological time series. Ecology 73:289-305.
Let us consider the integral

$$
\int_{t_{0}}^{\infty}\left[\int_{x_{0}}^{x(t)} L(x) \exp \left(-\alpha\left(t-t_{0}\right)\right) d x\right] d t
$$

where $x(t)$ is a monotonic function, $x\left(t_{0}\right)=x_{0}$, and $L(x)$ is a non-negative function. The integral (A.1) can be simplified:

$$
\int_{x_{0}}^{x(\infty)} L(x)\left[\int_{t(x)}^{\infty} \exp \left(-\alpha\left(t-t_{0}\right)\right) d t\right] d x=\int_{x_{0}}^{x(\infty)} \frac{L(x)}{\alpha} e^{-\alpha t(x)} d x
$$

where $t(x)$ is the inverse of function $x(t)$. After substituting the variable $x$ by $t$, we get

$$
\int_{t_{0}}^{\infty} \frac{L(x(t))}{\alpha} \exp \left(-\alpha\left(t-t_{0}\right)\right) v(t) d t
$$

where $v(t)=x^{\prime}(t)$

\section{APPENDIX A}

Proof of EQ. 4

The integral in Eq. 3 taken over the shaded area in Fig. 4 can be considered as a difference of two integrals of form (A.1): the first for the uncontrolled spread $x(t)=\min \left(x_{0}+\right.$ $\left.t v_{\max }, x_{\max }\right)$; and the second for the actual spread $x(t)$. The first integral can be simplified by substituting the variable $t$ by variable $x$ :

$$
\begin{aligned}
& \int_{t_{0}}^{\infty} \frac{L\left(\min \left(x_{0}+t v_{\max }, x_{\max }\right)\right)}{\alpha} \exp \left(-\alpha\left(t-t_{0}\right)\right) v(t) d t \\
&=\int_{x_{0}}^{x_{\max }} \frac{L(x)}{\alpha} \exp \left[-\frac{\alpha\left(x-x_{0}\right)}{v_{\max }}\right] d x
\end{aligned}
$$

The difference between integrals (A.4) and (A.3), multiplied by the average damage per unit area, $D$, gives Eq. 4 .

\section{APPENDIX B}

Optimal Management of Population Spread in a Rectangular Area

We assume that at current time, $t_{0}$, the population front is located at a point $x_{0}\left(0<x_{0}<x_{\max }\right)$. The optimal function $x(t)$ can be either monotonically increasing or monotonically decreasing, because for each location $x$, there is only one direction in which it is optimal to move the population front. The interval of integration in the second term of Eq. 4 can be taken from $t_{0}$ to $t_{\max }$, where $t_{\text {max }}$ is defined either by $x\left(t_{\max }\right)$ $=x_{\max }($ if $v(t)>0)$, or by $x\left(t_{\max }\right)=0$ (if $v(t)<0$ ). In the time interval from $t_{0}$ to $t_{\max }$, the length of the population front, $L(x(t))$, is constant. Thus, the second term in Eq. 5 has a minimum if and only if the integral

$$
\int_{t_{0}}^{t_{\max }}\left[\frac{D x^{\prime}(t)}{\alpha}+C\left(x^{\prime}(t)\right)\right] \exp \left[-\alpha\left(t-t_{0}\right)\right] d t
$$

has a minimum. The optimal function $x(t)$ can be found using the Euler equation (Elsgolts 1962):

$$
\frac{d}{d t}\left(\frac{\partial F}{\partial x^{\prime}}\right)-\frac{\partial F}{\partial x}=0
$$

where $x^{\prime}=v=d x / d t$ and

$$
F\left(t, x, x^{\prime}\right)=\left[\frac{D x^{\prime}}{\alpha}+C\left(x^{\prime}\right)\right] \exp \left[-\alpha\left(t-t_{0}\right)\right] .
$$

The Euler equation yields the following differential equation, which can be used for estimating the optimal target rate of population spread:

$$
v^{\prime}=\left(D+\alpha \frac{d C}{d v}\right)\left(\frac{d^{2} C}{d v^{2}}\right)^{-1}
$$

where $v^{\prime}=d v / d t=d^{2} x / d t^{2}$ is acceleration of spread.

The stationary rate of spread, $v^{*}$, can be found from Eq. B.4 by setting $v^{\prime}=0$. Then, $D+\alpha\left[d C\left(v^{*}\right) / d v\right]=0$, which is equivalent to Eq. 6. Thus, the stationary rate of spread is equal to the optimal target rate of spread in the infinitely long strip.

The stationary rate of spread, $v^{*}$, is unstable in Eq. B.4 because a small increase in the rate of spread causes the increase of $d C / d v$ (the cost function, $C(v)$, is concave), and the acceleration, $v^{\prime}$, becomes positive. Thus, possible solutions of Eq. B.4 are lines that deviate up and down from the 
FIG. B1. Solutions of Eq. B.4: (A) rate of spread, $v$, plotted against time, $t$ (the upper branch of the solution is limited by the rate of uncontrolled spread, $v_{\max }$ ); (B) the location, $x$, of the population front plotted against time; (C) the rate of spread plotted against the location of the population front.

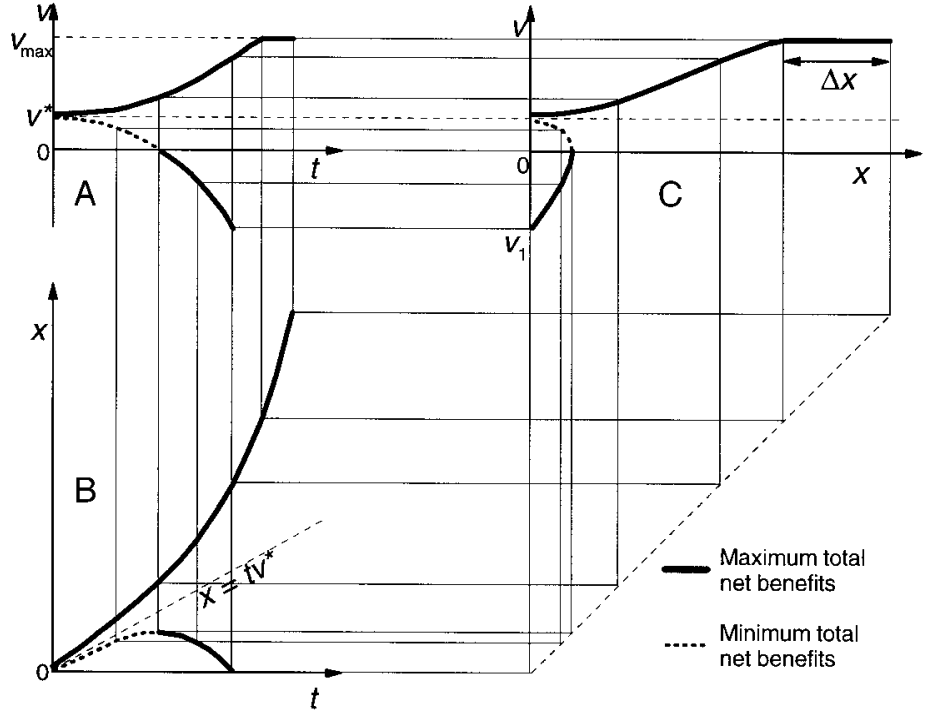

stationary rate of spread, $v^{*}$ (Fig. B1A). The portion of these functions with values $\min \left(0, v^{*}\right)<v<\max \left(0, v^{*}\right)$ correspond to the minimum of total net benefits; thus, they do not represent optimal rates of spread. The portions of lines with values $v<\min \left(0, v^{*}\right)$ and $v>\max \left(0, v^{*}\right)$ correspond to local maxima of total net benefits; thus, they may represent optimal spread rates. The position of the population front (Fig. B1B) is estimated as the integral of the rate of spread (Fig. B1A). Finally, the rate of spread is expressed as a function of the position of the population front (Fig. B1C).

We do not consider rates of spread that exceed the uncontrolled rate, $v_{\max }$, because then benefits become negative. Thus, when the optimal rate of spread reaches the uncontrolled rate $\left(v=v_{\max }\right)$, management terminates and the population continues expanding its range with the rate of $v_{\max }$.

To find particular solutions of Eq. B.4, we used two boundary conditions: one for slowing population spread and another for eradication. Both boundary conditions describe the situation at the moment when pest management is used for the last time. This is either abandoning of slowing the spread when the population front comes too close to the end of the area that potentially can become infested, or completing the eradication program.

The boundary condition for slowing the spread is derived as follows. Let us assume that the distance to the end of the area is $\Delta x$, and the rate of spread is $v\left(v \leq v_{\max }\right)$ for a short time, $\Delta t$, which is much smaller than the time left until the population reaches the end of the area $\left(\Delta x / v_{\max }\right)$. After time $\Delta t$, population spread is not managed $\left(v=v_{\max }\right)$. The present value of total net benefits (Eq. 5) is approximately equal to

$\mathrm{TNB}=\frac{D L}{\alpha}\left(v_{\max }-v\right)\left[1-\exp \left(1-\alpha \Delta x / v_{\max }\right)\right] \Delta t-L C(v) \Delta t$ where the first term represents benefits and the second term represents costs. Slowing the population spread is terminated when the derivative $d \mathrm{TNB} / d v=0$ at $v=v_{\max }$. Applying this condition to Eq. B.5, we get

$$
-C^{\prime}\left(v_{\max }\right)=\frac{D}{\alpha}\left[1-\exp \left(-\alpha \frac{\Delta x}{v_{\max }}\right)\right] .
$$

The boundary condition for slowing the population spread is the following: management of the rate of spread terminates when the distance to the end of the area is equal to $\Delta x$ (Eq. B.6).

Now we will derive the boundary condition for eradication. Let us assume that the population has been reduced to such total net benefits and assume a constant (negative) rate of spread. Time left until complete eradication is proportional to $(-1 / v)$. Thus, total costs are proportional to $[-C(v) / v]$. The optimal rate of spread corresponds to a minimum of this expression, which can be found by setting the derivative equal to zero:

The optimal rate of spread, $v$, at the end of eradication ( $x$ $=0$ ) is the solution of Eq. B.7. This is the boundary condition for eradication. If Eq. B.7 has no solutions for $v<\min (0$, $\left.v^{*}\right)$, then eradication should be completed in one step. a small size that we can ignore the damage component of

$$
v \frac{d C}{d v}-C(v)=0
$$

